\title{
Delafloxacin: Place in Therapy and Review of Microbiologic, Clinical and Pharmacologic Properties
}

\author{
Sarah C. J. Jorgensen - Nicholas J. Mercuro · Susan L. Davis • \\ Michael J. Rybak
}

Received: February 20, 2018 / Published online: March 31, 2018

(C) The Author(s) 2018

\begin{abstract}
Delafloxacin (formerly WQ-3034, ABT492, RX3341 ) is a novel fluoroquinolone chemically distinct from currently marketed fluoroquinolones with the absence of a protonatable substituent conferring a weakly acidic character to the molecule. This property results in increased intracellular penetration and enhanced bactericidal activity under acidic conditions that characterize the infectious milieu at a number of sites. The enhanced potency and penetration in low $\mathrm{pH}$ environments contrast what has been observed for

Enhanced content To view enhanced content for this article go to https://doi.org/10.6084/m9.figshare.59992 01 .
\end{abstract}

S. C. J. Jorgensen · N. J. Mercuro · S. L. Davis ·

M. J. Rybak ( $\varangle)$

Anti-Infective Research Laboratory, Eugene

Applebaum College of Pharmacy and Health

Sciences, Wayne State University, Detroit, MI, USA

e-mail:m.rybak@wayne.edu

N. J. Mercuro · S. L. Davis

Department of Pharmacy Services, Henry Ford

Hospital, Detroit, MI, USA

M. J. Rybak

Division of Infectious Diseases, Department of

Medicine, School of Medicine, Wayne State

University, Detroit, MI, USA

M. J. Rybak

Department of Pharmacy Services, Detroit Medical

Center, Detroit, MI, USA other zwitterionic fluoroquinolones, which tend to lose antibacterial potency under acidic conditions, and may be particularly advantageous against methicillin-resistant Staphylococcus aureus, for which the significance of the intracellular mode of survival is increasingly being recognized. Delafloxacin is also unique in its balanced target enzyme inhibition, a property that likely explains the very low frequencies of spontaneous mutations in vitro. Delafloxacin recently received US Food and Drug Administration approval for the treatment of acute bacterial skin and skin structure infections and is currently being evaluated in a phase 3 trial among patients with community-acquired pneumonia. In the current era of a heightened awareness pertaining to collateral ecologic damage, safety issues and antimicrobial stewardship principles, it is critical to describe the unique properties of delafloxacin and define its potential role in therapy. The purpose of this article is to review available data pertaining to delafloxacin's biochemistry, pharmacokinetic/pharmacodynamics characteristics, in vitro activity and potential for resistance selection as well as current progress in clinical trials to ultimately assist clinicians in selecting patients who will benefit most from the distinctive properties of this agent.

Keywords: Acute bacterial skin and skin structure infection; Antimicrobial stewardship; 
Delafloxacin; Fluoroquinolone; Methicillinresistant Staphylococcus aureus

\section{INTRODUCTION}

Fluoroquinolones are among the most commonly prescribed antibiotics, accounting for 23 million and 3.8 million oral and injectable prescriptions in the US in 2011, respectively [1, 2]. Attractive features of this class include their favorable pharmacokinetic (PK) properties, broad spectrum of activity and clinical efficacy for a wide range of commonly encountered infections [3]. However, paralleling the widespread use of fluoroquinolones has been an alarming increase in the prevalence of fluoroquinolone resistance among clinically relevant pathogens, underscoring the critical need to consider antimicrobial stewardship principles when defining the place in therapy of novel agents to ensure their utility is not short lived $[4,5]$.

Delafloxacin (formerly WQ-3034, ABT492, RX-3341), a novel dual-targeting anionic fluoroquinolone with useful in vitro activity against methicillin-resistant Staphylococcus aureus (MRSA), recently received US Food and Drug Administration (FDA) approval for the treatment of acute bacterial skin and skin structure infections (ABSSSIs) and is currently being evaluated in a phase 3 trial for the treatment of community-acquired pneumonia (CAP) [6]. Fluoroquinolones have not traditionally been among the first-line options for ABSSSI; however, delafloxacin's unique structural and chemical characteristics, which result in enhanced potency and intracellular penetration under acidic conditions, suggest it has the potential to fill a distinctive therapeutic niche for certain difficult-to-treat infections [7]. Furthermore, its dual targeting mechanism may serve to limit the emergence of resistance [8]. The purpose of this article is to critically review available data pertaining to delafloxacin's biochemistry, pharmacokinetic/pharmacodynamics (PK/PD) characteristics, in vitro activity and potential for resistance selection as well as current progress in clinical trials to ultimately delineate future research priorities and assist clinicians in selecting patients most likely to benefit from the distinctive properties of this agent.

\section{Compliance with Ethics Guidelines}

This article is based on previously conducted studies and does not contain any studies with human participants or animals performed by any of the authors.

\section{Data Sources}

Literature searches of MEDLINE (1946 to July 2017) and EMBASE (1974 to July 2017) were conducted using the search terms "ABT-492," "WQ-3034," "RX-3341" and "delafloxacin." Results were limited to articles available in English. Additional citations were identified from the references of relevant literature. Current trials focusing on delafloxacin were identified from clinicaltrials.gov. FDA review documents for the ABSSSI indication were also examined. Lastly, data were obtained from conference proceedings and published abstracts.

\section{CHEMISTRY AND MECHANISM OF ACTION}

The fluoroquinolone class of antibiotics exerts antimicrobial activity by inhibiting the two key enzymes, DNA gyrase and topoisomerase IV, which are essential for replication [9]. Although all fluoroquinolones in clinical use are active against both enzymes, they differ in relative inhibitory potency, with DNA gyrase as the more sensitive target among gram-negative bacteria and topoisomerase IV as the preferential target among gram-positive pathogens [9]. Delafloxacin demonstrates more balanced activity against both enzymes [8]. In theory, equipotent enzyme inhibition should serve to limit resistance selection since double mutations are relatively rare genetic events [10].

Delafloxacin demonstrates minimum inhibitory concentrations (MICs) that are consistently three- to five-fold lower than comparator 
fluoroquinolones against gram-positive organisms. This is thought to be derived in part from its greater affinity for DNA gyrase compared with other fluoroquinolones. Because DNA gyrase acts ahead of the replication fork to remove positive supercoils, it inhibits DNA replication more rapidly than the interaction with topoisomerase IV, which acts behind it and, as noted, is the preferential target of comparator fluoroquinolones [11]. Delafoxacin's increased potency against gram-positive bacteria is also related to its specific shape, size and polarity [12]. Distinguishing structural characteristics include the presence of a sizable substituted heteroaromatic ring at N1, the absence of a basic group at $\mathrm{C} 7$ and weak polarity defined by the chlorine atom at C8 (Fig. 1) [12]. The heteroaromatic ring at $\mathrm{N} 1$ increases the solventaccessible surface area, and collaboration between this large substituent and the weakly polar group at C8 is thought to influence potency against quinolone-resistant gram-positive bacteria [12]. It is hypothesized that this C8 substitution could also reduce second-step resistance development in $S$. aureus $[13,14]$. The absence of a basic group at $\mathrm{C} 7$ gives delafloxacin an anionic character at neutral $\mathrm{pH}$ [7]. This latter characteristic is unlike the majority of other fluoroquinolones, which exist as zwitterions at physiologic $\mathrm{pH}$ [7]. Under the acidic conditions that characterize the local environment at many infection sites (urinary tract,

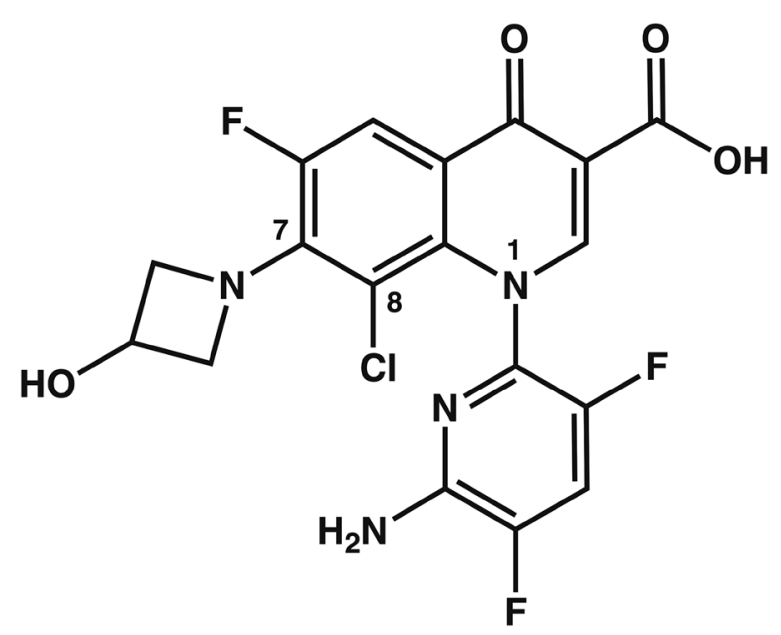

abscess fluid, decubitis ulcers, epithelial lining fluid and phagolysosomes of infected cells), delafloxacin exists predominantly in the neutral form, which favors uptake by both eukaryotic cells and bacteria [7]. This is accompanied by increased activity against both extra- and intracellular pathogens, in particular $S$. aureus, and contrasts what has been observed for other agents (fluoroquinolones, macrolides, aminoglycosides), which lose antibacterial potency under acidic conditions [7]. Delafloxacin MICs against a diverse range of gram-negative and positive organisms decrease four- to seven-fold as $\mathrm{pH}$ in the surrounding media is reduced from 7.2 to 5.5 [15]. The reduction in MICs are most pronounced among gram-positive bacteria [15].

\section{MICROBIOLOGY}

The in vitro activity of delafloxacin and comparator fluoroquinolones against a diverse range of gram-positive and -negative bacteria are presented in Tables 1 and 2. Minimum inhibitory concentration $\left(\mathrm{MIC}_{90}\right.$, range) values are representative of pooled data from studies conducted with delafloxacin with preference for studies conducted using isolates collected within the last 5 years $[16,17]$. Standard MIC determination methods are conducted under neutral $\mathrm{pH}$ conditions, and these values may give a conservative estimate of delafloxacin activity under acidic physiologic conditions.

Among contemporary $S$. aureus isolates (MSSA and MRSA), delafloxacin MIC $_{50 / 90}$ values were $\leq 0.004 / 0.25 \mathrm{mg} / \mathrm{l}$, respectively [18-20]. For a number of bacterial species, including $S$. aureus, delafloxacin MICs were bimodal (0.002-0.003 and $0.06-4 \mathrm{mg} / \mathrm{l})$, presumably because of existing fluoroquinolone resistance within the population [20]. Applying the FDA $S$. aureus delafloxacin susceptibility MIC breakpoint of $0.25 \mathrm{mg} / \mathrm{l}$ to the cumulative MIC values from a diverse collection of contemporary isolates from US and European medical centers yields susceptibility rates of $98.7 \%$ and $88.0 \%$ for MSSA and MRSA, respectively [6, 19]. The corresponding levofloxacin susceptibility rates were $89.8 \%$ and $30 \%$, respectively [19].

Fig. 1 Chemical structure of delafloxacin 
Table 1 In vitro activity (MIC, mg/l) of delafloxacin and comparators against aerobic gram-positive bacteria. Adapted from references [18-20, 23]

\begin{tabular}{|c|c|c|c|c|c|c|c|}
\hline \multirow[t]{2}{*}{ Organism } & \multirow[t]{2}{*}{ Phenotype } & \multicolumn{2}{|c|}{ Delafloxacin } & \multicolumn{2}{|c|}{ Levofloxacin } & \multicolumn{2}{|c|}{ Moxifloxacin } \\
\hline & & $\mathrm{MIC}_{90}$ & Range & $\mathrm{MIC}_{90}$ & Range & $\mathrm{MIC}_{90}$ & Range \\
\hline \multirow[t]{3}{*}{ Staphylococcus aureus } & All & 0.25 & $\leq 0.004$ to 4 & $>4$ & $\begin{array}{l}\leq 0.12 \\
\text { to }>4\end{array}$ & & \\
\hline & MSSA & 0.015 & $\leq 0.004$ to 4 & 2 & $\begin{array}{l}\leq 0.12 \\
\quad \text { to }>4\end{array}$ & & \\
\hline & MRSA & 0.5 & $\leq 0.004$ to 4 & $>4$ & $\begin{array}{l}\leq 0.12 \\
\quad \text { to }>4\end{array}$ & & \\
\hline \multirow[t]{3}{*}{$\begin{array}{l}\text { Coagulase-negative } \\
\text { Staphylococci }\end{array}$} & All & 0.5 & $\leq 0.004$ to 2 & 1 & $\begin{array}{l}\leq 0.12 \\
\quad \text { to }>4\end{array}$ & & \\
\hline & MSCoNS & 0.03 & $\leq 0.004$ to 1 & 4 & $\begin{array}{l}\leq 0.12 \\
\quad \text { to }>4\end{array}$ & & \\
\hline & MRCoNS & 1 & $\leq 0.004$ to 2 & $>4$ & $\begin{array}{l}\leq 0.12 \\
\quad \text { to }>4\end{array}$ & & \\
\hline \multirow[t]{3}{*}{ Enterococcus faecalis } & All & 1 & $\leq 0.004$ to 2 & $>4$ & $\begin{array}{l}0.25 \\
\quad \text { to }>4\end{array}$ & & \\
\hline & VSE & 1 & $\leq 0.004$ to 2 & $>4$ & $\begin{array}{l}0.25 \\
\quad \text { to }>4\end{array}$ & & \\
\hline & VRE & 1 & $\leq 0.008$ to 2 & $>4$ & $>4$ & & \\
\hline \multirow[t]{3}{*}{ Enterococcus faecium } & All & $>4$ & 0.008 to $>4$ & $>4$ & 0.5 to $>4$ & & \\
\hline & VSE & $>4$ & 0.008 to $>4$ & $>4$ & $>4$ & & \\
\hline & VRE & $>4$ & $>4$ & $>4$ & $>4$ & & \\
\hline \multirow[t]{7}{*}{ Streptococcus pneumoniae } & All & 0.03 & $\begin{aligned} \leq & 0.004 \text { to } \\
& 0.25\end{aligned}$ & 1 & 0.5 to $>4$ & 0.25 & $\leq 0.12$ to 4 \\
\hline & PSSP & 0.03 & $\begin{aligned} \leq & 0.004 \text { to } \\
& 0.03\end{aligned}$ & 1 & 0.5 to 1 & & \\
\hline & PISP & 0.015 & 0.008 to 0.15 & 1 & 0.5 to 1 & & \\
\hline & PRSP & 0.03 & 0.008 to 0.03 & 1 & 0.5 to 1 & 0.25 & $\begin{aligned} \leq & 0.12 \text { to } \\
& 0.25\end{aligned}$ \\
\hline & MDR & 0.015 & $\begin{aligned} \leq & 0.004 \text { to } \\
& 0.12\end{aligned}$ & 1 & 0.5 to $>4$ & 0.25 & $\leq 0.12$ to 4 \\
\hline & $\begin{array}{l}\text { Ceftriaxone non- } \\
\text { susceptible }\end{array}$ & NR & $\begin{aligned} \leq & 0.004 \text { to } \\
& 0.015\end{aligned}$ & NR & 1 to 2 & & $\begin{aligned} \leq & 0.12 \text { to } \\
& 0.25\end{aligned}$ \\
\hline & Levofloxacin resistant & 0.5 & 0.015 to 1 & 32 & 2 to 32 & 4 & 0.25 to $>4$ \\
\hline Streptococcus pyogenes & & 0.015 & $\begin{aligned} \leq & 0.004 \text { to } \\
& 0.03\end{aligned}$ & 1 & $\begin{array}{l}0.25 \\
\quad \text { to }>4\end{array}$ & 0.25 & $\begin{array}{c}\leq 0.12 \text { to } \\
0.5\end{array}$ \\
\hline
\end{tabular}


Table 1 continued

\begin{tabular}{|c|c|c|c|c|c|c|c|}
\hline \multirow[t]{2}{*}{ Organism } & \multirow[t]{2}{*}{ Phenotype } & \multicolumn{2}{|c|}{ Delafloxacin } & \multicolumn{2}{|c|}{ Levofloxacin } & \multicolumn{2}{|c|}{ Moxifloxacin } \\
\hline & & $\mathrm{MIC}_{90}$ & Range & $\mathrm{MIC}_{90}$ & Range & $\mathrm{MIC}_{90}$ & Range \\
\hline Streptococcus agalactiae & & 0.03 & $\begin{array}{l}\leq 0.004 \text { to } \\
0.5\end{array}$ & 1 & $\begin{array}{l}0.25 \\
\quad \text { to }>4\end{array}$ & 0.25 & $\begin{array}{l}\leq 0.12 \\
\quad \text { to }>4\end{array}$ \\
\hline Streptococcus dysgalaciae & & 0.015 & $\begin{aligned} \leq & 0.004 \text { to } \\
& 0.03\end{aligned}$ & 1 & $\begin{array}{l}0.25 \\
\quad \text { to }>4\end{array}$ & 0.25 & $\begin{aligned} \leq & 0.12 \text { to } \\
& 0.25\end{aligned}$ \\
\hline $\begin{array}{l}\text { Viridans group } \\
\text { Streptococci }\end{array}$ & & 0.06 & $\leq 0.004$ to 2 & 2 & $\begin{array}{l}\leq 0.12 \\
\quad \text { to }>4\end{array}$ & 0.25 & $\leq 0.12$ to 4 \\
\hline $\begin{array}{l}\text { Streptococcus anignosus } \\
\text { group }\end{array}$ & & 0.015 & $\begin{array}{c}0.008 \text { to } \\
0.015\end{array}$ & 0.5 & 0.5 & & \\
\hline Streptococcus mitis group & & 0.06 & 0.03 to 0.06 & 2 & 1 to 2 & & \\
\hline Listeria monocytogenes & & 0.12 & 0.06 to 0.12 & 1 & 1 & & \\
\hline
\end{tabular}

$M I C$ minimum inhibitory concentration, MRCoNS methicillin-resistant coagulase-negative staphylococcus, $M R S A$ methicillin-resistant Staphylococcus aureus, MSCoNS methicillin-susceptible coagulase-negative staphylococcus, MSSA methicillin-susceptible Staphylococcus aureus, NA not applicable, NR not reported, PISP penicillin-intermediate Streptococcus pneumoniae, PRSP, penicillin-resistant Streptococcus pneumoniae, PSSP penicillin-susceptible Streptococcus pneumoniae, VRE vancomycin-resistant enterococcus, $V S E$ vancomycin-susceptible enterococcus

McCurdy et al. recently evaluated the activity of delafloxacin against a global collection of $S$. aureus isolates $(n=687)$ from skin and skin structure infections, of which $34 \%$ demonstrated the levofloxacin-resistant phenotype [18]. Among levofloxacin-susceptible strains, delafloxacin showed excellent in vitro activity, and MIC values were not affected by the methicillin-resistant phenotype ( $\mathrm{MIC}_{90}$ $0.008 \mathrm{mg} / \mathrm{l}$ for both MSSA and MRSA). Delafloxacin maintained increased activity against levofloxacin-resistant MSSA and MRSA isolates; however, the $\mathrm{MIC}_{90}$ values were increased 32 -fold $(0.25 \mathrm{mg} / \mathrm{l})$ compared with levofloxacinsusceptible strains [18], which does raise questions pertaining to the risk of selecting resistant mutants during treatment, particularly in high inoculum $S$. aureus infections. Resistance selection studies have indeed demonstrated fewer passages are required to select mutants with increased MICs among fluoroquinolone-resistant $S$. aureus strains compared with sensitive strains [20]. In the study by McCurdy et al., only three $(0.4 \%)$ levofloxacin-resistant MRSA isolates had MIC values above the current delafloxacin $S$. aureus breakpoint [18].

Delafloxacin also demonstrated potent activity against $S$. pneumoniae, and, similar to earlier respiratory fluoroquinolones, its activity extends to strains displaying penicillin-resistant or ceftriaxone non-susceptible phenotypes [19-22]. In a 2014 surveillance study, all European and $98 \%$ of US $S$. pneumoniae isolates were inhibited by delafloxacin $\leq 0.03 \mathrm{mg} / \mathrm{l} \quad[19]$. These values are similar to those obtained in a bacterial respiratory surveillance program conducted 12 years earlier throughout Canada (CROSS), suggesting that delafloxacin, like other respiratory fluoroquinolones but in contrast to ciprofloxacin, has maintained its potency against $S$. pneumoniae despite the selective pressure of fluoroquinolone use during the intervening period [21]. Approximately 1\% of isolates in the US/European surveillance study displayed a levofloxacin-resistant 
Table 2 In vitro activity (MIC, mg/l) of delafloxacin and comparators against aerobic gram-negative bacteria. Adapted from references $[11,18-20,23,24]$

\begin{tabular}{|c|c|c|c|c|c|c|c|}
\hline \multirow[t]{2}{*}{ Organism } & \multirow[t]{2}{*}{ Phenotype } & \multicolumn{2}{|c|}{ Delafloxacin } & \multicolumn{2}{|c|}{ Levofloxacin } & \multicolumn{2}{|c|}{ Ciprofloxacin } \\
\hline & & $\mathrm{MIC}_{90}$ & Range & $\mathrm{MIC}_{90}$ & Range & $\mathrm{MIC}_{90}$ & Range \\
\hline \multirow[t]{2}{*}{ Escherichia coli } & All & 4 & $\begin{array}{r}\leq 0.004 \\
\text { to }>4\end{array}$ & $>4$ & $\begin{array}{l}\leq 0.12 \\
\quad \text { to }>4\end{array}$ & $>4$ & $\begin{array}{l}\leq 0.03 \\
\text { to }>4\end{array}$ \\
\hline & ESBL & $>4$ & $\begin{array}{l}0.008 \\
\quad \text { to }>4\end{array}$ & $>4$ & $\begin{array}{l}\leq 0.12 \\
\text { to }>4\end{array}$ & $>4$ & $\begin{array}{l}\leq 0.03 \\
\quad \text { to }>4\end{array}$ \\
\hline \multirow[t]{2}{*}{ Klebsiella pneumoniae } & All & $>4$ & $\begin{array}{l}0.015 \\
\quad \text { to }>4\end{array}$ & $>4$ & $\begin{aligned} \leq & 0.12 \\
& \text { to }>4\end{aligned}$ & & \\
\hline & ESBL & $>4$ & 0.06 to $>4$ & $>4$ & $\begin{array}{l}\leq 0.12 \\
\text { to }>4\end{array}$ & & \\
\hline Klebseilla oxytoca & & 0.12 & 0.03 to 1 & $\leq 0.12$ & $\begin{array}{l}\leq 0.12 \text { to } \\
1\end{array}$ & 0.06 & $\begin{array}{l}\leq 0.03 \\
\text { to }>4\end{array}$ \\
\hline \multirow[t]{2}{*}{ Proteus mirabilis } & All & 2 & $\begin{array}{l}0.015 \\
\quad \text { to }>4\end{array}$ & $>4$ & $\begin{array}{l}\leq 0.12 \\
\text { to }>4\end{array}$ & $>4$ & $\begin{array}{l}\leq 0.03 \\
\text { to }>4\end{array}$ \\
\hline & ESBL & $>4$ & 2 to $>4$ & $>4$ & $>4$ & & \\
\hline Enterobacter spp. & & 1 & $\begin{array}{l}\leq 0.004 \\
\quad \text { to }>4\end{array}$ & 0.5 & $\begin{aligned} \leq & 0.12 \\
& \text { to }>4\end{aligned}$ & 0.25 & $\begin{array}{l}\leq 0.03 \\
\quad \text { to }>4\end{array}$ \\
\hline Citrobacter spp. & & 2 & $\begin{array}{l}0.008 \\
\quad \text { to }>4\end{array}$ & 0.5 & $\begin{array}{l}\leq 0.12 \\
\text { to }>4\end{array}$ & 0.5 & $\begin{array}{l}\leq 0.03 \\
\quad \text { to }>4\end{array}$ \\
\hline Serratia spp. & & 2 & 0.03 to $>4$ & 1 & $\begin{array}{l}\leq 0.12 \\
\text { to }>4\end{array}$ & 1 & $\begin{array}{l}\leq 0.03 \\
\text { to }>4\end{array}$ \\
\hline Providencia spp. & & 0.12 & 0.008 to 0.5 & 0.25 & $\begin{array}{c}0.12 \text { to } \\
0.25\end{array}$ & & \\
\hline Morganella morganii & & 4 & 0.12 to 4 & $>4$ & $\begin{array}{l}\leq 0.12 \\
\text { to }>4\end{array}$ & & \\
\hline Proteus spp. & Indole-positive & 4 & $\begin{array}{l}0.008 \\
\quad \text { to }>4\end{array}$ & $>4$ & $\begin{array}{l}\leq 0.12 \\
\text { to }>4\end{array}$ & $>4$ & $\begin{array}{l}\leq 0.03 \\
\text { to }>4\end{array}$ \\
\hline Salmonella spp. & & 0.06 & 0.008 to 0.5 & 0.06 & 0.015 to 1 & 0.015 & $\begin{array}{l}0.002 \text { to } \\
0.25\end{array}$ \\
\hline Shigella spp. & & NR & $\begin{array}{c}0.002 \text { to } \\
0.008\end{array}$ & NR & $\begin{array}{c}0.004 \text { to } \\
0.015\end{array}$ & & \\
\hline Pseudomonas aeruginosa & & $>4$ & $\begin{array}{l}0.015 \\
\text { to }>4\end{array}$ & $>4$ & $\begin{array}{l}\leq 0.12 \\
\text { to }>4\end{array}$ & $>4$ & $\begin{array}{l}\leq 0.03 \\
\quad \text { to }>4\end{array}$ \\
\hline $\begin{array}{l}\text { Acinetobacter baumannii-A. } \\
\text { calcoaceticus }\end{array}$ & & $>4$ & $\begin{array}{l}0.015 \\
\quad \text { to }>4\end{array}$ & $>4$ & $\begin{array}{l}\leq 0.12 \\
\text { to }>4\end{array}$ & $>4$ & $\begin{array}{l}0.06 \\
\quad \text { to }>4\end{array}$ \\
\hline
\end{tabular}


Table 2 continued

\begin{tabular}{|c|c|c|c|c|c|c|c|}
\hline \multirow[t]{2}{*}{$\overline{\text { Organism }}$} & \multirow[t]{2}{*}{ Phenotype } & \multicolumn{2}{|c|}{ Delafloxacin } & \multicolumn{2}{|c|}{ Levofloxacin } & \multicolumn{2}{|c|}{ Ciprofloxacin } \\
\hline & & $\mathrm{MIC}_{90}$ & Range & $\mathrm{MIC}_{90}$ & Range & $\mathrm{MIC}_{90}$ & Range \\
\hline \multirow[t]{2}{*}{ Burkholder cepacia } & $\begin{array}{c}\text { Ciprofloxacin } \\
\text { susceptible }\end{array}$ & NR & 0.25 & NR & 1 & NR & 1 \\
\hline & $\begin{array}{l}\text { Ciprofloxacin } \\
\text { resistant }\end{array}$ & 16 & 0.25 to 16 & $>128$ & 2 to $>128$ & $>128$ & 2 to $>128$ \\
\hline Haemophilus influenza & & 0.004 & $\begin{aligned} \leq & 0.001 \text { to } \\
& 0.25\end{aligned}$ & 0.03 & $\begin{array}{l}0.008 \\
\quad \text { to }>2\end{array}$ & 0.015 & $\begin{array}{l}0.004 \\
\quad \text { to }>2\end{array}$ \\
\hline Moraxella catarrhalis & & 0.008 & $\begin{array}{c}0.004 \text { to } \\
0.015\end{array}$ & 0.06 & $\begin{array}{c}0.03 \text { to } \\
0.12\end{array}$ & 0.06 & $\begin{array}{c}0.015 \text { to } \\
0.06\end{array}$ \\
\hline Neisseria gonorrhea & & 0.06 & 0.125 & & & 16 & $\begin{array}{l}0.004 \\
\quad \text { to }>16\end{array}$ \\
\hline
\end{tabular}

ESBL extended-spectrum beta-lactamase, $M I C$ minimum inhibitory concentration, $N A$ not applicable, $N R$ not reported

phenotype (MIC $>4 \mathrm{mg} / \mathrm{l}$ ), and all were inhibited by delafloxacin $\leq 0.25 \mathrm{mg} / \mathrm{l}$ [19].

Delafloxacin is also very active against gramnegative respiratory pathogens. Haemophilus influenzae and Moraxella catarrhalis $\mathrm{MIC}_{90}$ values were $\leq 0.004$ and $0.008 \mathrm{mg} / \mathrm{l}$, respectively [22]. Due to the paucity of clinical data pertaining to outcomes with the use of delafloxacin for the treatment of respiratory tract infections at this time, the clinical breakpoints for these three pathogens have not yet been established.

The $\mathrm{MIC}_{90}$ value of contemporary Enterococcus faecalis isolates from both clinical and surveillance studies was $1 \mathrm{mg} / \mathrm{l}$ with a range of $\leq 0.004$ to $2 \mathrm{mg} / \mathrm{l}$ (Table 1) [18-20, 23] Among levofloxacin-resistant E. faecalis isolates, delafloxacin's $\mathrm{MIC}_{50 / 90}$ values were 0.25 and $8 \mathrm{mg} / \mathrm{l}$, respectively [23]. In the absence of clinical efficacy or PK/PD studies conducted with $E$. faecalis, the interpretive breakpoint of $\leq 0.12 \mathrm{mg} / \mathrm{l}$ was established by the FDA, which is many fold lower than the observed MIC $_{90}$ values [20]. As shown in Table 1, delafloxacin is not expected to have useful activity against $E$. faecium $\left(\mathrm{MIC}_{90}>4 \mathrm{mg} / \mathrm{l}\right)[19,20]$.

The in vitro activity of delafloxacin and fluoroquinolone comparators against a broad range of contemporary aerobic gram-negative bacteria is presented in Table 2. As shown, delafloxacin $\mathrm{MIC}_{90}$ values for E. coli and Klebsiella pneumoniae exceed the clinical breakpoint of $\leq 0.25 \mathrm{mg} / \mathrm{l}$ by 16 -fold and $>16$-fold, respectively $[19,20]$. The levofloxacin-resistant phenotype was observed in approximately 30\% and $20 \%$ of isolates, respectively, in these studies $[19,20]$. In the surveillance study by Pfaller et al., delafloxacin susceptibility rates among US E. coli and $K$. pneumoniae isolates were $65 \%$ and $78 \%$, respectively [19]. Among isolates with the ESBL phenotype, susceptibility rates were just $17.3 \%$ and $5.7 \%$, respectively [19]. Against Enterobacter spp., delafloxacin appears less active than levofloxacin. Delafloxacin demonstrated more potent activity against $K$. oxytoca with $\mathrm{MIC}_{90}$ values of $0.12 \mathrm{mg} /$ $1[19,20]$. As shown in Table 2, delafloxacin activity against Pseudomonas aeruginosa $\left(\mathrm{MIC}_{50}\right.$ ${ }_{90} 0.25 / 4 \mathrm{mg} / \mathrm{l} ; 65 \%$ susceptible) is similar to comparator anti-pseudomonal fluoroquinolones [19, 20].

Clinical experience with the indicated gramnegative pathogens has been very limited with most non-surveillance isolates cultured from poly-microbial infections in ABSSSI studies 
$[18,20]$. If the use of delafloxacin is contemplated for infections in which gram-negative bacilli are common pathogens, additional clinical data are needed to better determine how MIC values measured by standard methods should inform treatment decisions.

Delafloxacin has shown excellent in vitro activity against Neisseria gonorrheae including ciprofloxacin-resistant and multidrug-resistant (MDR) strains (Table 2) [24]. Against a panel of $N$. gonorrheae clinical isolates collected from medical centers across the US during 2012 to 2015 , including $67.5 \%$ with the ciprofloxacinresistant phenotype, the delafloxacin $\mathrm{MIC}_{90}$ value was $0.125 \mathrm{mg} / \mathrm{l}$ [24]. Lessons from the past however have shown that findings from in vitro studies may not be entirely predictive of clinical outcomes for $N$. gonorrheae infection [25]. Unfortunately, a phase 3 trial comparing a single oral dose of delafloxacin (900 mg) to ceftriaxone for the treatment of uncomplicated gonorrhea (NCT02015637) was terminated early in 2015 for reasons of insufficient efficacy following an independent interim review [26].

The in vitro activity of delafloxacin against Mycobacterium tuberculosis and M. avium was evaluated in a single study [27]. Delafloxacin was more efficacious than levofloxacin at inhibiting intracellular macrophage growth of M. tuberculosis. It is hypothesized that this observation may be related to improved delivery of delafloxacin to the phagosomes of MM6$\mathrm{M} \phi s$ that engulf bacteria. Additionally, the potentiation of delafloxacin's antimicrobial activity under the acidic conditions that are characteristic of the macrophage phagosomes that engulf mycobacterial pathogens may be particularly advantageous [27]. Further support for delafloxacin's ability to accumulate and exert antibacterial activity within mammalian cells comes from demonstrations of its activity against Chlamydia spp., an obligate intracellular pathogen, with MICs ranging from 0.03 to $0.06 \mathrm{mg} / \mathrm{l}[11]$.

Few studies have evaluated the activity of delafloxacin against clinically relevant anaerobic organisms [11, 28]. Potent activity was demonstrated against Bacteroides fragilis in particular in one study, with an $\mathrm{MIC}_{90}$ value of $0.125 \mathrm{mg} / \mathrm{l}$ [28]. Caution is advised when interpreting the findings because isolates were collected nearly 15 years ago, and in the intervening period fluoroquinolone resistance among key anaerobic bacteria has increased significantly [16, 29]. More recent US surveillance data testing isolates collected during 2010 to 2012 have shown much lower susceptibility rates for moxifloxacin against key anaerobic species $[16,29]$. Although the potential for cross-resistance among anaerobic species for delafloxacin and other fluoroquinolones has not been explored, high levels of cross-resistance have been documented between earlier fluoroquinolones.

More contemporary data pertaining to delafloxacin's activity against Clostridium difficile has been presented. Vernon et al. investigated the in vitro activity of delafloxacin and comparator agents against prevalent $C$. difficile ribotypes (RTs) [30]. Delafloxacin's geometric mean (GM) MIC overall was $0.37 \mathrm{mg} / \mathrm{l}$. Large differences in activity were observed for isolates belonging to the hypervirulent RT027 compared with non-RT027 (GM MIC 4.0, $0.13 \mathrm{mg} / \mathrm{l}$, respectively), suggesting delafloxacin shares in the universal fluoroquinolone class resistance in this troublesome strain [30].

\section{PHARMACOKINETICS}

The PK properties of delafloxacin have been evaluated in phase 1 and 3 studies utilizing single and multiple ascending doses ranging from 300 to $1200 \mathrm{mg}$ (IV) and 50 to $1600 \mathrm{mg}$ (oral) [31-33]. As shown in Table 3, at steady state, delafloxacin, administered as $300 \mathrm{mg}$ IV every $12 \mathrm{~h}$, achieves a maximum serum concentration $\left(C_{\max }\right)$ of $9.29 \mathrm{mg} / \mathrm{l}$ and total exposure (AUC from 0 to $12 \mathrm{~h}, \mathrm{AUC}_{\tau}$ ) of $23.4 \mathrm{mg} \mathrm{h} / \mathrm{l}$. The bioavailability of the tablet formulation is $59 \%$, which is lower than that of other fluoroquinolones such as levofloxacin and moxifloxacin (99\% and 92\%, respectively; Table 3); however, the $\mathrm{AUC}_{\tau}$ of delafloxacin $450 \mathrm{mg}$ administered orally ( $20.6 \mathrm{mg} \mathrm{h} / \mathrm{l})$ is comparable to that achieved with a labeled IV dose of $300 \mathrm{mg}$ [6, 32-34]. Both the IV and oral formulations demonstrate approximate dose proportional increases in exposure following single 
Table 3 Pharmacokinetic parameters of delafloxacin and comparator fluoroquinolones. Adapted from references $[6,33-35]$

\begin{tabular}{|c|c|c|c|c|c|}
\hline Parameter & $\begin{array}{l}\text { Delafloxacin IV } \\
(300 \mathrm{mg} \text {, every } \\
12 \mathrm{~h})\end{array}$ & $\begin{array}{l}\text { Delafloxacin PO } \\
(450 \mathrm{mg} \text {, every } \\
12 \mathrm{~h})\end{array}$ & $\begin{array}{l}\text { Levofloxacin PO } \\
(750 \mathrm{mg} \text {, every } \\
24 \mathrm{~h})\end{array}$ & $\begin{array}{l}\text { Ciprofloxacin PO } \\
(500 \mathrm{mg} \text {, every } \\
12 \mathrm{~h})\end{array}$ & $\begin{array}{l}\text { Moxifloxacin PO } \\
(400 \mathrm{mg} \text {, every } \\
12 \mathrm{~h})\end{array}$ \\
\hline$V_{\mathrm{d}}(\mathrm{l})$ & $35-48$ & & 100 & $84-189^{a}$ & $119-189^{a}$ \\
\hline$C_{\max }(\mathrm{mg} / \mathrm{l})$ & 9.29 & 7.45 & 8.6 & 3.0 & 4.5 \\
\hline$f C_{\max }(\mathrm{mg} / \mathrm{l})$ & 1.49 & 1.19 & $5.3-6.5$ & $1.8-2.4$ & $2.25-3.15$ \\
\hline $\begin{array}{l}\mathrm{AUC}_{0-\tau} \\
\quad(\mathrm{mg} \mathrm{h} / \mathrm{l})\end{array}$ & 30.8 & 23.4 & 90.7 & 13.7 & 48 \\
\hline $\begin{array}{l}f \mathrm{AUC}_{0-\tau} \\
\qquad(\mathrm{mg} \mathrm{h} / \mathrm{l})\end{array}$ & 4.93 & 3.74 & $56.2-68.9$ & $8.2-11.0$ & $24-33.6$ \\
\hline$\underset{\mathrm{AUC}}{\mathrm{AUC}_{24}(\mathrm{mg} \mathrm{h} /}$ & 61.6 & 46.8 & 90.7 & 27.4 & 48 \\
\hline $\begin{array}{l}\mathrm{fAUC}_{24}(\mathrm{mg} \mathrm{h} / \\
\mathrm{l})\end{array}$ & 9.86 & 7.48 & $56.2-68.9$ & $16.4-22.0$ & $24-33.6$ \\
\hline Protein binding & $84 \%$ & & $24-38 \%$ & $20-40 \%$ & $30-50 \%$ \\
\hline$T_{1 / 2}(\mathrm{~h})$ & $3.7^{\mathrm{b}}$ & $4.2-8.5$ & 8.8 & $4-6$ & $10-14$ \\
\hline $\begin{array}{l}\text { Elimination } \\
\quad \text { (urine:feces) }\end{array}$ & $64.5 \%: 28.4 \%^{\mathrm{b}}$ & $50.2 \%: 47.7 \%$ & $87 \%: 4 \%$ & $57 \%: 20-35 \%$ & 20\%:25\% \\
\hline $\begin{array}{l}\text { Oral } \\
\text { bioavailability }\end{array}$ & $\mathrm{N} / \mathrm{A}$ & $58.8 \%$ & $99 \%$ & $70 \%$ & $92 \%$ \\
\hline Metabolism & Glucuronidation $^{c}$ & & Limited? & Oxidation? & $\begin{array}{l}\text { Sulfation, } \\
\text { glucuronidation }\end{array}$ \\
\hline
\end{tabular}

$V_{d}$ volume of distribution, $C_{\max }$ peak serum concentration, $f C_{\max }$ free peak concentration, $A U C_{0-\tau}$ area under the curve over the dosing interval, $f A U C_{0-\tau}$ free area under the curve over the dosing interval, $A U C_{24}$ area under the curve over $24 \mathrm{~h}$, $f A U C_{24}$ free area under the curve over $24 \mathrm{~h}, T_{1 / 2}$ half- life

${ }^{\text {a }}$ Based on a $70-\mathrm{kg}$ adult

b After a single dose

c No significant circulating metabolites

doses ranging up to 1200 and $1600 \mathrm{mg}$, respectively [32, 33]. The $C_{\max }$ is reduced $20 \%$, and the time to $C_{\max }\left(T_{\max }\right)$ is doubled when delafloxacin tablets are administered with food compared with the fasting state. However, total delafloxacin exposure $\left(\mathrm{AUC}_{\tau}\right)$ is similar when administered with or without food; thus, PK changes secondary to food intake around the time of dosing are not expected to affect clinical outcomes $[32,33]$.
Delafloxacin volumes of distribution have ranged from 35 to $48 \mathrm{l}$ across studies. Protein binding (primarily to albumin) is approximately 84\% (Table 3) [6, 33-35]. Delafloxacin shares the fluoroquinolone class characteristic of high pulmonary distribution with a 13:1 mean penetration ratio into the epithelial lining fluid vs. free plasma concentration [36]. Data pertaining to the distribution characteristics of delafloxacin in other tissues have not been reported at this time. 
Delafloxacin is primarily metabolized through glucuronidation, with oxidative metabolism accounting for approximately $1 \%$ of the administered dose, suggesting a low potential for drug interactions. The predominant route of elimination is renal (50-65\%) with the remainder of elimination occurring in the feces as unchanged drug. Delafloxacin's half-life was $3.7 \mathrm{~h}$ following a single IV $300 \mathrm{mg}$ dose and ranged from 4.2 to $8.5 \mathrm{~h}$ following multiple oral doses [6, 33, 37].

PK parameters of delafloxacin have been examined in patients with varying degrees of renal impairment [33]. Delafloxacin exposure has consistently been shown to increase with decreasing renal function; however, clinically important differences are not apparent until the estimated glomerular filtration rate (eGFR) as calculated using the Modification of Diet in Renal Disease equation (MDRD) is under $30 \mathrm{ml} /$ $\min / 1.73 \mathrm{~m}^{2}$. The $\mathrm{AUC}_{\tau}$ increased 1.8-fold in patients with severe renal impairment (eGFR $15-29 \mathrm{ml} / \mathrm{min} / 1.73 \mathrm{~m}^{2}$ ) following a single $300 \mathrm{mg}$ IV dose. The corresponding fold changes in total exposure among patients with endstage renal disease (ESRD) when delafloxacin was administered before and after hemodialysis (HD) were 2.1 and 2.6, respectively. Decreased plasma protein binding has also been observed in subjects with severe renal impairment and ESRD (80\% and 75\%, respectively). Based on population PK simulations, an adjusted dose of $200 \mathrm{mg}$ IV every $12 \mathrm{~h}$ is recommended for patients with severe renal impairment $[6,33]$. The lower dose also reduces the risk for adverse renal effects secondary to sulfobutylether-betacyclodextrin (SBECD, an excipient in the IV formulation) accumulation [33].

Decreasing renal function does not appear to greatly impact the exposure of delafloxacin tablets; drug exposure was 1.5-fold higher in subjects with severe renal impairment following oral administration (450 mg) compared with subjects with normal renal function. A dosing regimen of $450 \mathrm{mg}$ IV every $12 \mathrm{~h}$ produced exposures in patients with normal renal function similar to those achieved in patients with severe renal impairment that were administered the $450-\mathrm{mg}$ oral dose, and tolerability was acceptable at these exposures [33]. Thus, dosage adjustment of the oral formulation for patients with severe renal impairment is not recommended. Currently, there are no explicit labeled recommendations for dosing in patients maintained on HD. Twenty percent of the drug is removed during a 4-h HD session [6].

The PK profile of delafloxacin has been evaluated in subjects with varying degrees of hepatic impairment. Total AUC values were similar in patients with normal, mild and moderate hepatic function. Higher PK variability was observed in patients with severe hepatic impairment, and total exposure was increased approximately $40 \%$ compared with controls. These differences are unlikely to be clinically important, and dosage adjustment in this population is not recommended [33].

\section{PHARMACODYNAMICS}

Similar to other fluoroquinolones, delafloxacin exhibits concentration-dependent antimicrobial activity, and the unbound drug AUC over $24 \mathrm{~h}$ divided by the MIC of the pathogen $\left(f \mathrm{AUC}_{24} / \mathrm{MIC}\right)$ is the $\mathrm{PK} / \mathrm{PD}$ parameter most closely associated with delafloxacin activity $[33,38]$. The PD target value for delafloxacin against $S$. aureus was determined in a series of experiments using the murine neutropenic thigh infection model [33]. Animals were inoculated with $10^{6} \mathrm{CFU}$ of MSSA or MRSA possessing delafloxacin MICs ranging from 0.004 to $0.006 \mathrm{mg} / \mathrm{l}$ and 0.016 to $0.8 \mathrm{mg} / \mathrm{l}$, respectively. Delafloxacin $(1.25$ to $320 \mathrm{mg} / \mathrm{kg})$ was administered as a single dose, and the bacterial burden was determined $24 \mathrm{~h}$ after dosing. The median $\mathrm{fAUC}_{24} / \mathrm{MIC}$ ratios associated with net bacterial stasis and a $1-\log _{10}$ CFU reduction were 9.3 and 14.3, respectively. Utilizing a murine lung infection model for collection of MSSA and MRSA isolates with MICs ranging from 0.004 to $0.008 \mathrm{mg} / \mathrm{l}$, Andes et al. documented substantially lower median target ratios (stasis 1.74 and $1-\log _{10}$ CFU reduction 7.92) [39]. Similarly, the median $f \mathrm{AUC}_{24} / \mathrm{MIC}$ ratio of delafloxacin to achieve either stasis or $1-\log _{10}$ CFU reduction in a neutropenic murine lung model by Thabit et al. utilizing MSSA isolates (MIC $0.002-0.52 \mathrm{mg} / \mathrm{l}$ ) was 0.4 [36]. However, the 
corresponding target ratios for MRSA isolates with baseline MICs of $0.25-1 \mathrm{mg} / \mathrm{l}$ were markedly higher in this study (stasis 8.1 and $1-\log _{10}$ CFU reduction 24.7) and more closely aligned to those generally quoted for fluoroquinolones against gram-positive cocci $\left(\right.$ fAUC $\left._{24} / \mathrm{MIC} \geq 25\right)$ $[36,38]$. Thus, it appears that PK/PD targets for delafloxacin may differ between stains, phenotypes and site of infection.

Similar experiments were also conducted to determine the threshold $f \mathrm{AUC}_{24} / \mathrm{MIC}$ ratios associated with efficacy against $E$. coli and $P$. aeruginosa. Findings indicated mean $f \mathrm{AUC}_{24} /$ MIC targets for bacterial stasis and a $1-\log _{10} \mathrm{CFU}$ reduction for $E$. coli were 14.5 and 26.2, respectively, while the corresponding $f \mathrm{AUC}_{24} /$ MIC targets for P. aeruginosa were 3.8 and 5.0, respectively.

Staphylococcus aureus is frequently associated with biofilm-related infections, which are particularly difficult to treat because antibiotics tend to be much less active against bacteria embedded in biofilm compared with those in the planktonic state [40]. The increased potency of delafloxacin under acidic conditions may be particularly advantageous in this setting [7]. Utilizing an in vitro PD model of mature $S$. aureus biofilms, Bauer et al. reported that delafloxacin reduced both MSSA and MRSA biofilm viability by at least $50 \%$ at clinically achievable concentrations [41]. Delafloxacin, oxacillin (MSSA) and daptomycin were the most efficacious among a panel of nine anti-staphylococcal agents. The interpretation of these findings is somewhat hampered by the use of reference $S$. aureus strains displaying MICs that are 4(MSSA) and 125-fold (MRSA) lower than $\mathrm{MIC}_{90}$ values documented in contemporary surveillance studies [41].

In a second biofilm study using MSSA and MRSA with a broader range of delafloxacin MIC values (0.004-0.125 mg/l), delafloxacin displayed potent activity at clinically achievable concentrations against five of the seven isolates tested [42]. Investigators did not account for delafloxacin protein binding (84\%) when considering achievable $C_{\max }$ values in vivo however. The penetration of delafloxacin within the biofilm was observed to range from $0.62 \%$ to $51.8 \%$ and was generally greater in biofilms with lower $\mathrm{pH}$ values [42].

Renal abscesses involving $S$. aureus are challenging to treat with currently available agents because of the presence of a large proportion of bacteria in the stationary phase of growth, and the local environment is usually characterized by low $\mathrm{pH}$ values [7]. Ding et al. investigated the comparative activity of delafloxacin and moxifloxacin against renal abscesses formed by a community-associated MRSA strain (MW2) in a murine model of systemic infection [43]. Both delafloxacin and moxifloxacin reduced the bacterial load in renal abscesses compared with controls. The reduction of the bacterial burden by delafloxacin was significantly greater than that by moxifloxacin [43].

Delafloxacin has also demonstrated increased activity against gram-negative pathogens under acidic experimental conditions. So et al. examined the effect of urine matrix and its varying $\mathrm{pH}$ on the activity of delafloxacin and ciprofloxacin against 16 MDR urogenic E. coli and K. pneumoniae [44]. All isolates were resistant to both ciprofloxacin (MIC 32 to $>64 \mathrm{mg}$ / 1) and delafloxacin (MIC $2-16 \mathrm{mg} / \mathrm{l}$ ) at baseline when measured in standard media. Similar to results obtained for delafloxacin against grampositive pathogens tested under acidic experimental conditions [7], delafloxacin MICs decreased by $1-3$ doubling dilutions in $53 \%$ and $68 \%$ of observations for E. coli and K. pneumoniae, respectively, when MIC testing was performed in acidic urine. By contrast, MICs for ciprofloxacin remained relatively unchanged across the range of $\mathrm{pH}$ values tested [7]. Even with the maximal MIC reductions when using urine as the test media, most isolates would continue to demonstrate MICs far above the current delafloxacin Enterobacteriaceae interpretive breakpoint of $\leq 0.25 \mathrm{mg} / \mathrm{l}$; thus, the clinical implications of this study as relates to the potential utility of delafloxacin in the treatment of MDR Enterobacteriaceae are not entirely clear $[6,44]$. 


\section{RESISTANCE}

Resistance to fluoroquinolones most commonly involves step-wise chromosomal mutations in the quinolone resistance-determining regions (QRDR) of DNA gyrase (gyrA) and/or topoisomerase IV (parC/grlA). Overexpression of efflux pumps and decreased uptake secondary to reduced expression of outer membrane porins may also contribute to chromosomal resistance $[9$, 45]. Finally, plasmid-mediated fluoroquinolone resistance is an emerging concern [45].

Delafloxacin maintains clinically useful activity against a range of bacteria displaying the quinolone-resistant phenotype secondary to single and double mutations in the QRDR as well as efflux pump expression. The ability of delafloxacin to select for spontaneous mutations within the QRDR or efflux pump gene loci in vitro has been investigated in a number of studies using both naïve strains and those with pre-existing mutations. Remy et al. conducted a series of spontaneous resistance selection experiments using four strains of $S$. aureus, three of which carried pre-existing mutations in the QRDR [8]. The observed resistance frequencies were low $\left(6.0 \times 10^{-9}\right.$ to $\left.<9.5 \times 10^{-9}\right)$ for delafloxacin at two times the baseline MIC and similar to those demonstrated for moxifloxacin [8]. The resistance frequencies of both drugs were substantially less than that of levofloxacin. Notably, no delafloxacin-resistant strains could be isolated from the strain that had no pre-existing QRDR mutations [6]. The minimum protective concentration in the present study ranged from one to four times the initial MIC for all quinolones tested. Delafloxacin-resistant mutants maintained their reduced susceptibility following passage in drug-free media for 7 days, suggesting a stable phenotype $[8,46]$.

Whole-genome sequencing characterized the nature of the mutations of the resultant variants. Delafloxacin-selected variants with MIC shifts $\leq 4$-fold of the parent strain showed no genetic changes in the QRDR or the norA loci, which encodes for the predominant fluoroquinolone efflux pump in $S$. aureus. Mutant strains with delafloxacin MICs $\geq 8$-fold those of the parent strain were characterized by both previously described and novel mutations in gryA and gyrB. Two variant isolates, both with MICs of $4 \mathrm{mg} / \mathrm{l}$ and selected from a parent strain with pre-existing gyrA and grlA mutations, showed no changes in the QRDR or the norA sequence and its surrounding regulatory regions, suggesting delafloxacin resistance may arise through previously uncharacterized mechanisms [8].

\section{CLINICAL EFFICACY}

The clinical efficacy of delafloxacin has been evaluated in phase 2 and phase 3 studies among patients with ABSSSI as well as phase 2 studies among patients with acute exacerbation of chronic obstructive pulmonary disease and CAP [47-52].

The first clinical study to evaluate delafloxacin in the treatment of ABSSSIs was a phase 2 randomized, double-blind, multicenter, doseranging comparative study [48]. Adults with wound infection, abscess or cellulitis were enrolled from 14 centers in the US; patients $(n=150)$ were randomized to delafloxacin 300 or $450 \mathrm{mg}$, each administered IV, every $12 \mathrm{~h}$ or tigecycline $100 \mathrm{mg}$ IV once, followed by $50 \mathrm{mg}$ $\mathrm{IV}$, every $12 \mathrm{~h}$ for 5-14 days [48]. S. aureus comprised nearly $90 \%$ of gram-positive pathogens, and methicillin-resistance was detected in $71 \%$. Clinical cure rates and microbiologic eradication rates exceeded $90 \%$ in all treatment groups with no between-group differences.

Kingsley et al. performed the second phase 2 ABSSSI multicenter, randomized, double-blind trial evaluating delafloxacin (300 mg) versus linezolid (600 mg) and vancomycin $(15 \mathrm{mg} / \mathrm{kg}$, actual body weight; maximum $1250 \mathrm{mg}$; target trough $15-20 \mathrm{mg} / \mathrm{l})$, each administered IV twice daily for 5-14 days [47]. The addition of blinded aztreonam was permitted for patients with gram-negative infections randomized to linezolid or vancomycin. In total, 256 patients comprised the intention-to-treat population (ITT). S. aureus was the most frequently isolated organism with $67 \%$ of strains displaying the methicillin-resistant phenotype [47]. Cure rates 
at the follow-up time point (day 14) were $70.4 \%$ in the delafloxacin group compared with $64.9 \%$ in the linezolid group $(P=0.496$ vs. delafloxacin) and $54.1 \%$ in the vancomycin group $(P=0.031$ vs. delafloxacin). The higher cure rate in the delafloxacin vs. vancomycin group appeared to be driven by patients with a body mass index (BMI) $\geq 30 \mathrm{~kg} / \mathrm{m}^{2}$ (78.8\% vs. $48.8 \%$; $P=0.009)$. Among the microbiologically evaluable population $(n=125)$, presumed or documented eradication rates were similar between groups and ranged from $80.8 \%$ to $88.2 \%$ [47].

There are several limitations to these studies that deserve comment. Importantly, as phase 2 trials, they were not designed with a formal prespecified hypothesis or powered for any inferential statistical testing. Both trials included a relatively small number of patients and, as a consequence, the range of bacterial pathogens recovered was limited. Furthermore, patients most at risk for infection with a broader range of bacterial species (i.e., those who are immunocompromised or have severe underlying comorbidity) and who therefore may stand to benefit from delafloxacin's expanded spectrum of activity, were excluded from the studies. The MRSA MICs for delafloxacin were considerably lower than has been observed in recent surveillance studies [20, 47, 48]. All patients were enrolled from US centers, which raises the question of whether the data are applicable across geographic populations. Finally, although most patients were treated in the outpatient setting, the efficacy of the oral formulation of delafloxacin was not evaluated.

To address these limitations as well as fulfill regulatory drug approval requirements, two phase 3 studies evaluating delafloxacin for the treatment of adult patients with ABSSSIs were initiated in 2013 (NCT01811732/RX-3341-302 and NCT1984684/RX-3341-303, hereafter referred to as study 302 and 303, respectively) [51, 52]. Both were multicenter, randomized, doubleblind, non-inferiority studies comparing delafloxacin $(300 \mathrm{mg})$ with vancomycin $(15 \mathrm{mg} / \mathrm{kg}$ actual body weight) plus aztreonam ( $2 \mathrm{~g})$, each administered IV, every $12 \mathrm{~h}$ for 5-14 days $[51,52]$. In study 303 , a switch to oral delafloxacin (450 mg) was mandated following six IV doses except for patients with an eGFR 15-29 ml/ min who were to receive delafloxacin $200 \mathrm{mg}$ IV every $12 \mathrm{~h}$ for all doses $[51,52]$. If gram-negative pathogens were not isolated on the baseline culture, aztreonam was discontinued. No similar de-escalation to targeted therapy occurred for patients in the delafloxacin arms. Patients with infections involving prosthetic material or associated with human/animal bites, osteomyelitis, decubitus ulcer, diabetic foot ulcer, septic arthritis, necrotizing fasciitis or burns covering $\geq 10 \%$ of the body surface area were not eligible for enrollment. Other key exclusion criteria included severe underlying comorbidity (liver disease, end-stage renal disease, cardiac disease, malignancy), history of seizure disorder and pregnancy or lactation. The primary endpoint in the two studies was $\geq 20 \%$ reduction in lesion size at $48-72 \mathrm{~h}$ in the ITT population. In study 303, enrollment was expanded above the calculated sample size to enrich for a pre-specified subgroup analysis by BMI $[51,52]$.

In total, 660 and 850 patients were randomized in study 302 and 303, respectively. In both studies, the majority of patients were enrolled from US centers. The mean age of participants was approximately 46 and 50 years in study 302 and 303, respectively. Few patients aged 65 years and older were enrolled $(7 \%$ and $20 \%$, respectively). Approximately $80-90 \%$ of patients were Caucasian; African American patients were under-represented (7\% and 20\%). Obese patients (BMI $\geq 30 \mathrm{~kg} / \mathrm{m}^{2}$ ) comprised $32 \%$ and $40 \%$ of the study populations. Eight to $13 \%$ of patients carried a diagnosis of diabetes, and approximately $1 \%$ had severely decreased renal function (eGFR $<30 \mathrm{ml} / \mathrm{min}$ ). Bacteremia was rare in both studies $(2.3 \%, 2.2 \%)$ [51, 52].

The most prevalent pathogen isolated from the infection site was $S$. aureus, which was identified in $66 \%$ and $58 \%$ of the microbiologic ITT (MITT) patients in study 302 and 303, respectively. MRSA accounted for 52\% and 36\% of the $S$. aureus isolates, respectively [51, 52].

Delafloxacin was non-inferior to vancomycin plus aztreonam for the primary endpoint in both trials. Outcomes at the end of the therapy time point ( $14 \pm 1$ day) were similar, suggesting a sustained response to treatment in all groups. Importantly, outcomes at the later 
time points in study 303 are supportive of oral delafloxacin, which would have been initiated following assessment of the primary outcome. Among the MITT population, per pathogen response rates were generally similar between treatment groups across all pathogens. Overall, $66 \%$ of MRSA isolates were levofloxacin nonsusceptible [51]. Among these isolates, the delafloxacin $\mathrm{MIC}_{90}$ value was $0.25 \mathrm{mg} / \mathrm{l}$, and the eradication or presumed eradication rate was 98.6\%. One MRSA isolate displayed an MIC of $4 \mathrm{mg} / \mathrm{l}$, and double mutations in both gyrA and parC were subsequently confirmed. The microbiologic response for the patient with this isolate was presumed eradicated based on clinical response. Approximately $15 \%$ of isolates recovered were gram-negative. The predominant gram-negative pathogens were $K$. pneumoniae and $E$. coli. Levofloxacin non-susceptibility was low among $K$. pneumoniae (2.2\%), and most were susceptible to delafloxacin $\left(\mathrm{MIC}_{50 / 90} 0.12 /\right.$ $0.25 \mathrm{mg} / \mathrm{l})$. Levofloxacin non-susceptibility was slightly higher among E. coli, and the delafloxacin $\mathrm{MIC}_{90}$ was $4 \mathrm{mg} / \mathrm{l}$ [51].

Subgroup analysis by age, sex, race and geographic region were consistent with the overall results; however, analysis is limited by the small number of patients in some subgroups, particularly those from regions outside of the US and African American patients [51, 52].

In study 302, an exploratory post hoc analysis by BMI category suggested a significant improvement in cure rates at the long-term follow-up time point among obese patients assigned to delafloxacin compared with vancomycin $(71.7 \%$ vs. $57.5 \%$; treatment difference $14.2 \%, 95 \%$ CI $1.3 \%$ to $26.9 \%$ ) [51, 52]. This finding however was not subsequently confirmed in study 303, which, as noted previously, was enriched with obese patients to allow for formal statistical testing of this hypothesis. Among obese patients the cure rates at the late follow-up time point were similar $(68.3 \%$ vs. $71.0 \%$; treatment difference $-2.7 \%, 95 \%$ CI $-11.5 \%$ to $6.0 \%)$. Information pertaining to vancomycin trough target attainment has not been reported for the overall study populations or by BMI category $[51,52]$.

Although these studies addressed several limitations of the phase 2 studies including a larger number of patients and conducting formal hypothesis testing, they did not expand knowledge of delafloxacin's performance among patients at risk for a broader range of pathogens. Key populations including the elderly, those with organ dysfunction, and those with significant underlying comorbidity were either excluded or under-represented. Furthermore, although too few gram-negative isolates were collected to allow for meaningful analysis, the high delafloxacin MIC values displayed among those that were obtained suggest delafloxacin may not be an ideal option when these pathogens are suspected, although, as noted previously, MIC values determined by standard methods may underestimate in vivo activity.

The efficacy of delafloxacin has also been explored among patients with respiratory tract infections [49, 50]. Longcor et al. conducted a phase 2, double-bind, randomized, dose-ranging study comparing three dose ranges of oral delafloxacin $(100,200,400 \mathrm{mg}$ daily $\times 5$ days) to levofloxacin (500 mg daily $\times 7$ days) in adult outpatients diagnosed with ABECB [49]. In total, 280 patients were randomized with a mean age of 61 years. Clinical cure rates were similar in the four groups (69-79\%), and no dose-response trend was identified. Regarding bacteriologic cure rates, however, outcomes were improved among patients assigned to delafloxacin $400 \mathrm{mg}$ compared with the lower doses. In the phase 2 study evaluating the clinical and bacteriologic outcomes with ascending delafloxacin doses $(100,200$ or $400 \mathrm{mg}$ once daily for 7 day) among adult outpatients with CAP $(n=309)$, clinical and bacteriologic cure rates were similar in the 200 and $400 \mathrm{mg}$ groups and slightly lower for the $100 \mathrm{mg}$ group [50].

While the results of these studies are encouraging and appear to support a role for delafloxacin in the treatment of bacterial respiratory tract infections, further data from an ongoing phase 3 study comparing delafloxacin to moxifloxacin or linezolid for the treatment CAP (NCT02679573) are required before definitive conclusions pertaining to its efficacy for respiratory infections can be made. 


\section{ADVERSE EFFECTS}

For many years, fluoroquinolones were considered a safe and generally well-tolerated class of antimicrobials [53]. In recent decades, however, safety concerns have led to restrictions on the use of fluoroquinolones and, in some instances, withdrawal of agents from the market [53, 54]. Recently, the FDA advisory committees on antimicrobial drugs and drug safety concluded that a risk vs. benefit analysis did not support the use of these agents in a number of uncomplicated infections, and labeling of all marketed fluoroquinolones has been updated to include stronger warnings pertaining to the risks serious adverse effects (AEs) such as tendon rupture, peripheral neuropathy and central nervous system (CNS) disturbances [55]. Distinct differences among fluoroquinolones with regard to their safety profile can be predicted in part by structural differences with structure-AE relationships based on constituents at specific sites on the quinolone nucleus [54]. Delafloxacin has a number of unique structural characteristics, however, which present challenges when attempting to predict the potential for serious AEs by this approach.

As with all fluoroquinolones, the most commonly reported AEs in phase 3 delafloxacin trials were gastrointestinal (GI) related (diarrhea $8 \%$, nausea $8 \%$ ) or mild CNS events [56]. Data from phase 1 and 2 studies indicate an association between GI AEs and higher doses [56]. There does not appear to be a clear fluoroquinolone structure-GI AE relationship, but rather GI AEs are thought to be due to direct GI irritation and/or indirect CNS effects [53].

Tendinopathies are rare AEs associated with fluoroquinolones [57]. Although there has not been a widely accepted structural moiety associated with tendinopathy, animal models suggest structural differences at position 7 may play a role with a methypiperadinyl group causing the highest number of tendon lesions [57]. Delafloxacin is the only marketed fluoroquinolone with a weakly acidic substituent at this position [58]. Three patients in pooled phase 3 delafloxacin trials reported tendonitis [56]. One event was graded as moderate in severity, and all other events were considered to be mild. Predisposing factors such as concomitant steroid use and renal disease were not present in any of the affected patients [56].

AEs involving the CNS have generally been the second most commonly encountered form of fluoroquinolone toxicity and include a broad variety of effects ranging from headaches and dizziness to acute psychosis to seizures [54]. These effects are thought to occur secondary to fluoroquinolone blockade of GABA receptors $[53,54]$. In vitro experiments suggest that the delafloxacin concentrations required to inhibit GABA are many fold above those achieved clinically [56]. In line with these experimental observations, headache occurred in just 3\% of delafloxacin-treated patients in pooled phase 3 trials, and other CNS AEs were relatively rare [56]. No patients in the delafloxacin arms of phase 3 studies experienced seizures or convulsions [56]. One patient who received a higher than labeled dose of delafloxacin (450 mg IV) during a phase 2 study experienced a seizure [56].

Structural differences at positions 1, 5 and 8 of the quinolone nucleus influence the phototoxic potential [54]. Fluoroquinolones with a halogen at position 8 of the nucleus along with a bulky side chain are well known for their associated phototoxicity [53]. A methyl group at position 5 may also contribute [53]. Delafloxacin contains a chlorine at position 8 but lacks a bulky side chain and contains no R5 substituent [58]. A phase 1 study investigating the photosensitizing potential of delafloxacin demonstrated findings similar to placebo with no evidence of phototoxicity in either the low $(200 \mathrm{mg})$ or high $(400 \mathrm{mg})$ dose arms of delafloxacin-treated subjects [56]. By comparison, more subjects assigned to the positive control group (lomefloxacin) exhibited both mild and severe phototoxicity at various wavelengths.

Assessment of the hepatotoxic potential of delafloxacin is limited by the relatively small number of patients who have been exposed at this time. Although case reports of severe liver injury emerged soon after trovafloxacin was introduced into the clinic, it was not until approximately 2.5 million courses of therapy had been administered that the causal 
relationship was deemed strong enough to warrant its removal from the market [59]. The frequency of clinically significant elevations (> 5 times the upper limit of normal) of aspartate aminotransferase, alanine aminotransferase and alkaline phosphatase was $0.3 \%$ or less across delafloxacin groups in phase 3 trials, and no clinically significant elevations in bilirubin occurred [56]. These parameters may be poorly predictive of the potential for drug-induced hepatotoxicity however.

The main area of interest relating to the cardiac toxicity of fluoroquinolones is prolongation of the QTc interval [59]. The mechanism by which this occurs is likely multifactorial, and an obvious structural moiety that increases the risk for QTc prolongation has not yet been identified [54]. Studies of various fluoroquinolones have shown a dose-dependent inhibition of the rapid-acting portion of the delayed rectifier potassium current, which is controlled by the human ether-a-go-go gene (HERG) [60]. Preclinical studies with delafloxacin have found that it did not block HERG currents. In a phase 1 study delafloxacin doses up to three-fold higher than the currently labeled dose $(900 \mathrm{mg}$ ) did not induce clinically meaningful changes in the QTc, while moxifloxacin, which served as the positive control, produced predicted prolongation of the QTC interval $[56,61]$. In phase 3 studies, no occurrences of drug-induced arrhythmias were reported [56].

Administration of fluoroquinolones has emerged as one of the most important risk factors for $C$. difficile-associated diarrhea (CDAD) caused by the hypervirulent RT027 strain [62]. In early surveillance studies, delafloxacin demonstrated potent activity against many anaerobic species [28]. In particular, it showed greater in vitro activity against $C$. difficile than comparator fluoroquinolones; however, activity against the RT027 strain was considerably lower [30]. The impact of delafloxacin, of which $35-50 \%$ is eliminated unchanged in the feces, on bowel flora is unknown at this time. Two cases of CDAD were reported among patients enrolled in the delafloxacin arms of phase 2 and 3 studies [56]. Both patients were noted to have a number of risk factors for CDAD besides antibiotic exposure [56].

Fluoroquinolones are not known to commonly cause harmful effects on the kidneys; however, the vehicle used to deliver IV delafloxacin, SBECD, may be problematic in patients with renal impairment [63]. A reduced delafloxacin dose ( $200 \mathrm{mg}$ IV q12 h) is therefore recommended in patients with an eGFR < $30 \mathrm{ml} / \mathrm{min} / 1.73 \mathrm{~m}^{2}$ and a switch to oral delafloxacin as soon as clinically indicated [6].

To summarize, the available data have not demonstrated significant safety concerns for delafloxacin. However, as with all new antibiotics, assessment of safety is limited by the small number of healthy subjects and patients to whom it has been administered. Exclusion criteria in completed phase 3 trials also limit the generalizability of safety findings to patients who may be more likely to receive this agent in the clinic, i.e., those with pre-existing organ dysfunction and a higher degree of baseline comorbidities. Nevertheless, the additional quasi-experimental data, which included positive controls for two important class AEs, phototoxicity and QTc prolongation, are reassuring.

\section{DRUG INTERACTIONS}

Like other fluoroquinolones, delafloxacin forms insoluble chelation complexes with multivalent cations in the GI tract resulting in a substantial decrease in oral absorption of the antibiotic, and concomitant administration should be avoided [6]. At clinically relevant concentrations, delafloxacin does not inhibit cytochrome P450 isoenzymes 1A2, 2A6, 2B6, 2C8, 2C9, 2C19, 2D6, 2E1 or 3A4/5 [56]. Delafloxacin demonstrated mild induction of CYP3A4 at clinically relevant concentrations in vitro; however, it did not affect the $C_{\max }$ and AUC values for midazolam (a sensitive CYP3A4 substrate) or its metabolite when administered to healthy volunteers prior to midazolam administration [56]. Delafloxacin is a substrate of breast cancer-related protein (BCRP) and a potential substrate of P-glycoprotein [56]. However, only modest increases in delafloxacin concentrations are anticipated when co- 
administered with BCRP or P-glycoprotein inhibitors, and the clinical significance is expected to be minimal [56]. The impact of P-glycoprotein inducers, such as rifampicin, on delafloxacin exposure has not been reported.

\section{PLACE IN THERAPY AND CONCLUSIONS}

ABSSSI is a popular market-entry indication for pharmaceutical companies developing new antimicrobials targeting MRSA [64-67]. Delafloxacin recently received FDA approval in this setting based on registry studies showing it to be an effective and well-tolerated alternative [5]. Notable advantages of delafloxacin for the treatment of ABSSSI include the availability of both parenteral and oral formulations, a low potential for drug-drug interactions and reassuring clinical and experimental data pertaining to key class-adverse effects such as cardiotoxicity and phototoxicity. With the availability of a variety of new agents for the treatment of ABSSSI, it will be important to determine which agents are most suitable for specific patients on the basis of coverage (broad versus narrow spectrum), delivery (IV or PO) and potential for adverse reactions and compliance (single versus multiple daily dosing).

Of particular concern, fluoroquinolone use has been associated with increased rates of colonization and infection with MRSA, ESBL-producing Enterobacteriaceae and [5, 68-70] the hypervirulent $C$. difficile RT027 strain $[62,70]$. Recent international guidelines for the treatment of a number of infectious diseases explicitly recognize the ecologic AEs of fluoroquinolones as important factors in therapeutic decision-making and have called for more restricted use of these agents [71, 72]. As antibiotic innovation continues to move forward, greater attention needs to be placed on pinpointing unique properties of novel agents to assist in determining their specific therapeutic niche with respect to areas of unmet medical need while limiting collateral damage.

There are many important areas of unmet need in the treatment of gram-positive infections for which experimental data suggest the distinctive structural and chemical properties of delafloxacin may be harnessed to make it a particularly valuable addition to the antibiotic armamentarium. Improving long-term outcomes in patients with biofilm-associated infections is a critical unmet need, and delafloxacin's potent activity against $S$. aureus embedded in biofilm suggests a potential role in this setting [41, 42]. Antibiotics that are capable of eradicating intracellular non-replicating persister bacteria in bone, prosthetic device-associated infections and deep-seated abscesses are clearly an unmet medical need, and delafloxacin's excellent intracellular penetration, especially in the acidic conditions that are characteristic of these difficult to treat infections, points to another therapeutic niche [7]. A potent oral agent would be particularly desirable in these settings because prolonged therapy with IV antibiotics is often necessary but associated with tremendous expense, inconvenience and harmful effects associated with extended catheterization. The prospect of combination therapy with delafloxacin and rifampicin for these infections is intriguing, and future research investigating the potential synergistic activity in biofilm models would be valuable. Delafloxacin's bactericidal activity and excellent pulmonary penetration [36] are also suggestive of a promising role against pneumonia. The diminishing pool of effective antibiotics for gonorrhea represents an urgent public health threat [73]. Although a single oral dose of delafloxacin was not sufficiently effective for uncomplicated gonorrhea infection, its potent in vitro activity against this pathogen [24] suggests that evaluations of alternative dosing schedules would be worthwhile.

Struggles with resistance will not cease with the availability of new antibiotics, and we must learn how to optimally use and not abuse promising new agents such as delafloxacin. An oral antibiotic with in vitro activity against MRSA, Pseudomonas spp., anaerobes, and atypical organisms will attract many prescribers, and antimicrobial stewards will be tasked with implementing it appropriately into practice. As clinicians contemplate how to best incorporate delafloxacin into infectious disease treatment strategies, additional data pertaining to whether 
the promising experimental data detailed in this review do indeed translate into improved outcomes for patient with difficult to treat infections are greatly anticipated.

\section{ACKNOWLEDGEMENTS}

The authors acknowledge the contribution of Jeffrey M. Rybak, University of Tennessee, for drawing the chemical structure of delafloxacin.

Funding. No funding or sponsorship was received for this study or publication of this article.

Authorship. All named authors meet the International Committee of Medical Journal Editors (ICMJE) criteria for authorship for this article, take responsibility for the integrity of the work as a whole, and have given their approval for this version to be published.

Disclosures. Michael J. Rybak has received grant support, consulted or spoken on behalf of Accelerate, Allergan, Achaogen, Bayer, Merck, Melinta, The Medicine Company and Theravance. Susan L. Davis has served on the advisory board and/or been a consultant for Allergan, Melinta, The Medicine Company, Nabriva and Zavante. Sarah C. J. Jorgensen and Nicholas J. Mercuro have nothing to disclose.

Compliance with Ethics Guidelines. This article is based on previously conducted studies and does not contain any studies with human participants or animals performed by any of the authors.

Open Access. This article is distributed under the terms of the Creative Commons Attribution-NonCommercial 4.0 International License (http://creativecommons.org/licenses/ by-nc/4.0/), which permits any noncommercial use, distribution, and reproduction in any medium, provided you give appropriate credit to the original author(s) and the source, provide a link to the Creative Commons license, and indicate if changes were made.

\section{REFERENCES}

1. US Food and Drug Administration. IMS Health Vector One, National Total Patient Tracker. Extracted July 2012.

2. US Food and Drug Administration. ICHARUS. Extracted July 2012.

3. Wong-Beringer A, Nguyen LH, Lee M, Shriner KA, Pallares J. An antimicrobial stewardship program with a focus on reducing fluoroquinolone overuse. Pharmacotherapy. 2009;29(6):736-43.

4. Neuhauser MM, Weinstein RA, Rydman R, Danziger LH, Karam G, Quinn JP. Antibiotic resistance among gram-negative bacilli in US intensive care units: implications for fluoroquinolone use. JAMA. 2003;289(7):885-8.

5. Fuzi M. Has the use of fluoroquinolones facilitated the widespread dissemination of methicillin-resistant Staphylococcus aureus and extended-spectrum beta-lactamase-producing Klebsiella pneumoniae in the healthcare setting? Acta Microbiol Immunol Hung. 2014;61(4):399-405.

6. BAXDELA (delafloxacin) product package insert. Lincolnshire: Melinta Therapeutics, Inc. 2017.

7. Lemaire S, Tulkens PM, Van Bambeke F. Contrasting effects of acidic $\mathrm{pH}$ on the extracellular and intracellular activities of the anti-gram-positive fluoroquinolones moxifloxacin and delafloxacin against Staphylococcus aureus. Antimicrob Agents Chemother. 2011;55(2):649-58.

8. Remy JM, Tow-Keogh CA, McConnell TS, Dalton JM, Devito JA. Activity of delafloxacin against methicillin-resistant Staphylococcus aureus: resistance selection and characterization. J Antimicrob Chemother. 2012;67(12):2814-20.

9. Hooper DC. Mechanisms of action and resistance of older and newer fluoroquinolones. Clin Infect Dis. 2000;31(Suppl 2):S24-8.

10. Smith HJ, Nichol KA, Hoban DJ, Zhanel GG. Dual activity of fluoroquinolones against Streptococcus pneumoniae: the facts behind the claims. J Antimicrob Chemother. 2002;49(6):893-5.

11. Nilius AM, Shen LL, Hensey-Rudloff D, Almer LS, Beyer JM, Balli DJ, et al. In vitro antibacterial potency and spectrum of ABT-492, a new fluoroquinolone. Antimicrob Agents Chemother. 2003;47(10):3260-9.

12. Duffy M, DeVito JA, Remy J, Burbak ES. Delafloxacin chemical properties lead to increased potency against gram-positive pathogens, 
including quinolone-resistant pathogens II. In: 50th Interscience Conference on Antimicrobial Agents and Chemotherapy, September 12-15, 2010, Boston, MA, Abstract E-182.

13. Lu T, Zhao X, Li X, Drlica-Wagner A, Wang JY, Domagala J, et al. Enhancement of fluoroquinolone activity by C-8 halogen and methoxy moieties: action against a gyrase resistance mutant of $M y$ cobacterium smegmatis and a gyrase-topoisomerase IV double mutant of Staphylococcus aureus. Antimicrob Agents Chemother. 2001;45(10):2703-9.

14. Okumura R, Hirata T, Onodera Y, Hoshino K, Otani $\mathrm{T}$, Yamamoto T. Dual-targeting properties of the 3-aminopyrrolidyl quinolones, DC-159a and sitafloxacin, against DNA gyrase and topoisomerase IV: contribution to reducing in vitro emergence of quinolone-resistant Streptococcus pneumoniae. J Antimicrob Chemother. 2008;62(1):98-104.

15. Burbak ES, DeVito JA, Remy J, Duffy ME. Delafloxacin chemical properties lead to increased potency against gram-positive pathogens, including quinolone-resistant pathogens I. In: 50th Interscience Conference on Antimicrobial Agents and Chemotherapy, September 12-15, 2010, Boston, MA, Abstract E-182.

16. Clinical and Laboratory Standards Institute. Performance standards for antimicrobial susceptibility testing 27th informational supplement. CLSI document M100-S27. Wayne: CLSI; 2017.

17. Sahm DF, Thornsberry C, Jones ME, Karlowsky JA. Factors influencing fluoroquinolone resistance. Emerg Infect Dis. 2003;9(12):1651-4.

18. McCurdy S, Lawrence L, Quintas M, Woosley L, Flamm R, Tseng C, et al. In vitro activity of delafloxacin and microbiological response against fluoroquinolone-susceptible and nonsusceptible staphylococcus aureus isolates from two phase 3 studies of acute bacterial skin and skin structure infections. Antimicrob Agents Chemother. 2017;61(9). https://doi.org/10.1128/AAC.00772-17.

19. Pfaller MA, Sader HS, Rhomberg PR, Flamm RK. In vitro activity of delafloxacin against contemporary bacterial pathogens from the United States and Europe, 2014. Antimicrob Agents Chemother. 2017;61(4). https://doi.org/10.1128/AAC.02609-16.

20. Sheikh J. Clinical microbiology review. Delafloxacin. NDA\#208610, 208611. Melinta Therapeutics, Inc. Division of Anti-Infective Products. Center for Drug Evaluation and Research. US Food and Drug Administration; 2017.

21. Zhanel GG, Palatnick L, Nichol KA, Bellyou T, Low DE, Hoban DJ. Antimicrobial resistance in respiratory tract Streptococcus pneumoniae isolates: results of the Canadian Respiratory Organism Susceptibility Study, 1997 to 2002. Antimicrob Agents Chemother. 2003;47(6):1867-74.

22. Flamm RK, Rhomberg PR, Huband MD, Farrell DJ. In vitro activity of delafloxacin tested against isolates of Streptococcus pneumoniae, Haemophilus influenzae, and Moraxella catarrhalis. Antimicrob Agents Chemother. 2016;60(10):6381-5.

23. Almer LS, Hoffrage JB, Keller EL, Flamm RK, Shortridge VD. In vitro and bactericidal activities of ABT-492, a novel fluoroquinolone, against grampositive and gram-negative organisms. Antimicrob Agents Chemother. 2004;48(7):2771-7.

24. Soge OO, Salipante SJ, No D, Duffy E, Roberts MC. In vitro activity of delafloxacin against clinical Neisseria gonorrhoeae isolates and selection of gonococcal delafloxacin resistance. Antimicrob Agents Chemother. 2016;60(5):3106-11.

25. Tapsall JW, Shultz TR, Limnios EA, Donovan B, Lum G, Mulhall BP. Failure of azithromycin therapy in gonorrhea and discorrelation with laboratory test parameters. Sex Transm Dis. 1998;25(10):505-8.

26. Melinta Therapeutics. Melinta therapeutics ceases phases 3 proceeding study. Press release. http:// melinta.com/melinta-therapeutics-ceases-phase-3proceeding-study/. Accessed 20 Dec 2017.

27. Tomioka H, Sato K, Kajitani H, Akaki T, Shishido S. Comparative antimicrobial activities of the newly synthesized quinolone WQ-3034, levofloxacin, sparfloxacin, and ciprofloxacin against Mycobacterium tuberculosis and Mycobacterium avium complex. Antimicrob Agents Chemother. 2000;44(2):283-6.

28. Sillerstrom E, Wahlund E, Nord CE. In vitro activity of ABT-492 against anaerobic bacteria. J Chemother. 2004;16(3):227-9.

29. Golan Y, McDermott LA, Jacobus NV, Goldstein EJ, Finegold S, Harrell LJ, et al. Emergence of fluoroquinolone resistance among Bacteroides species. J Antimicrob Chemother. 2003;52(2):208-13.

30. Vernon J, Freeman J, Wilcox MH. Susceptibility of common Clostridium difficile PCR ribotypes to delafloxacin and seven comparator antimicrobials. In: 55th Interscience Conference on Antimicrobial Agents and Chemotherapy, September 17-21, 2015. San Diego, CA, Abstract 2408.

31. Hoover R, Hunt T, Benedict M, Paulson SK, Lawrence L, Cammarata S, et al. Safety, tolerability, and pharmacokinetic properties of intravenous delafloxacin after single and multiple doses in healthy volunteers. Clin Ther. 2016;38(1):53-65. 
32. Hoover R, Hunt T, Benedict M, Paulson SK, Lawrence $\mathrm{L}$, Cammarata $\mathrm{S}$, et al. Single and multiple ascending-dose studies of oral delafloxacin: effects of food, sex, and age. Clin Ther. 2016;38(1):39-52.

33. Wu K, Yan Z. Clinical pharmacology and biopharmaceutical review. Delafloxacin. NDA\#208610, 208611. Melinta Therapeutics, Inc. Division of Anti-Infective Products. Center for Drug Evaluation and Research. US Food and Drug Administration; 2017.

34. CIPRO (ciprofloxacin) product package insert. Whippany: Bayer Corp.; 2017.

35. AVELOX (moxifloxacin) product package insert. Kenilworth: Merck Co.; 2017.

36. Thabit AK, Crandon JL, Nicolau DP. Pharmacodynamic and pharmacokinetic profiling of delafloxacin in a murine lung model against community-acquired respiratory tract pathogens. Int J Antimicrob Agents. 2016;48(5):535-41.

37. McEwen A, Lawrence L, Hoover R, Stevens L, Mair S, Ford $G$, et al. Disposition, metabolism and mass balance of delafloxacin in healthy human volunteers following intravenous administration. Xenobiotica. 2015;45(12):1054-62.

38. Wright DH, Brown GH, Peterson ML, Rotschafer JC. Application of fluoroquinolone pharmacodynamics. J Antimicrob Chemother. 2000;46(5):669-83.

39. Lepak AJ, Andes DR. In vivo pharmacodynamic target assessment of delafloxacin against Staphylococcus aureus, Streptococcus pneumoniae, and Klebsiella pneumoniae in a murine lung infection model. Antimicrob Agents Chemother. 2016;60(8):4764-9.

40. Romling U, Balsalobre C. Biofilm infections, their resilience to therapy and innovative treatment strategies. J Intern Med. 2012;272(6):541-61.

41. Bauer J, Siala W, Tulkens PM, Van Bambeke F. A combined pharmacodynamic quantitative and qualitative model reveals the potent activity of daptomycin and delafloxacin against Staphylococcus aureus biofilms. Antimicrob Agents Chemother. 2013;57(6):2726-37.

42. Siala W, Mingeot-Leclercq MP, Tulkens PM, Hallin M, Denis O, Van Bambeke F. Comparison of the antibiotic activities of daptomycin, vancomycin, and the investigational fluoroquinolone delafloxacin against biofilms from Staphylococcus aureus clinical isolates. Antimicrob Agents Chemother. 2014;58(11):6385-97.

43. Ding Y, Villet RA, Lee JC, Hooper DC. Treatment of renal abscesses caused by Staphylococcus aureus MW2, using delafloxacin and moxifloxacin. In: 21th European Congress of Clinical Microbiology and Infectious Diseases, May 7-10, 2011. Milan, Italy, Abstract 1506.

44. So W, Crandon JL, Nicolau DP. Effects of urine matrix and $\mathrm{pH}$ on the potency of delafloxacin and ciprofloxacin against urogenic Escherichia coli and Klebsiella pneumoniae. J Urol. 2015;194(2):563-70.

45. Baudry-Simner PJ, Singh A, Karlowsky JA, Hoban DJ, Zhanel GG, Canadian Antimicrobial Resistance A. Mechanisms of reduced susceptibility to ciprofloxacin in Escherichia coli isolates from Canadian hospitals. Can J Infect Dis Med Microbiol. 2012;23(3):e60-4.

46. Firsov AA, Vostrov SN, Lubenko IY, Arzamastsev AP, Portnoy YA, Zinner SH. ABT492 and levofloxacin: comparison of their pharmacodynamics and their abilities to prevent the selection of resistant Staphylococcus aureus in an in vitro dynamic model. J Antimicrob Chemother. 2004;54(1):178-86.

47. Kingsley J, Mehra P, Lawrence LE, Henry E, Duffy E, Cammarata SK, et al. A randomized, double-blind, Phase 2 study to evaluate subjective and objective outcomes in patients with acute bacterial skin and skin structure infections treated with delafloxacin, linezolid or vancomycin. J Antimicrob Chemother. 2016;71(3):821-9.

48. O'Riordan W, Mehra P, Manos P, Kingsley J, Lawrence L, Cammarata S. A randomized phase 2 study comparing two doses of delafloxacin with tigecycline in adults with complicated skin and skinstructure infections. Int J Infect Dis. 2015;30:67-73.

49. Longcor J, Hopkins S, Wikler M, Lawrence L. A phase 2 safety and efficacy study of oral delafloxacin (DLX) in subjects with acute bacterial exacerbation of chronic bronchitis (ABECB). IDWeek, October 17-21, 2012, San Diego, CA, Abstract 1071.

50. Longcor J, Hopkins S, Wikler M, Lawrence L. A phase 2 safety and efficacy study of oral delafloxacin (DLX) in community acquired pneumonia (CAP). IDWeek, October 17-21, 2012, SanDiego, CA, Abstract 1069.

51. Charles JK. Statistical review. Delafloxacin. NDA\#208610, 208611. Melinta Therapeutics, Inc. Division of Anti-Infective Products. Center for Drug Evaluation and Research. US Food and Drug Administration; 2017.

52. Pullman J, Gardovskis J, Farley B, Sun E, Quintas M, Lawrence L, et al. Efficacy and safety of delafloxacin compared with vancomycin plus aztreonam for acute bacterial skin and skin structure infections: a phase 3, double-blind, randomized study. J Antimicrob Chemother. 2017;72(12):3471-80. 
53. Mandell LA, Ball P, Tillotson G. Antimicrobial safety and tolerability: differences and dilemmas. Clin Infect Dis. 2001;32(Suppl 1):S72-9.

54. Mehlhorn AJ, Brown DA. Safety concerns with fluoroquinolones. Ann Pharmacother. 2007;41(11):1859-66.

55. Tillotson GS. FDA and the safe and appropriate antibiotic use of fluoroquinolones. Lancet Infect Dis. 2016;16(3):e11-2.

56. Jjingo CJ. Clinical review. Delafloxacin. NDA\#208610, 208611. Melinta Therapeutics, Inc. Division of Anti-Infective Products. Center for Drug Evaluation and Research. US Food and Drug Administration; 2017.

57. Kashida Y, Kato M. Characterization of fluoroquinolone-induced Achilles tendon toxicity in rats: comparison of toxicities of 10 fluoroquinolones and effects of anti-inflammatory compounds. Antimicrob Agents Chemother. 1997;41(11):2389-93.

58. Candel FJ, Penuelas M. Delafloxacin: design, development and potential place in therapy. Drug Des Dev Ther. 2017;11:881-91.

59. Owens RC Jr, Ambrose PG. Antimicrobial safety: focus on fluoroquinolones. Clin Infect Dis. 2005;41(Suppl 2):S144-57.

60. Fish DN, North DS. Gatifloxacin, an advanced 8-methoxy fluoroquinolone. Pharmacotherapy. 2001;21(1):35-59.

61. Litwin JS, Benedict MS, Thorn MD, Lawrence LE, Cammarata SK, Sun E. A thorough QT study to evaluate the effects of therapeutic and supratherapeutic doses of delafloxacin on cardiac repolarization. Antimicrob Agents Chemother. 2015;59(6):3469-73.

62. Pepin J, Saheb N, Coulombe MA, Alary ME, Corriveau MP, Authier S, et al. Emergence of fluoroquinolones as the predominant risk factor for Clostridium difficile-associated diarrhea: a cohort study during an epidemic in Quebec. Clin Infect Dis. 2005;41(9):1254-60.

63. Luke DR, Tomaszewski K, Damle B, Schlamm HT. Review of the basic and clinical pharmacology of sulfobutylether-beta-cyclodextrin (SBECD). J Pharm Sci. 2010;99(8):3291-301.

64. Corey GR, Wilcox M, Talbot GH, Friedland HD, Baculik T, Witherell GW, et al. Integrated analysis of CANVAS 1 and 2: phase 3, multicenter, randomized, double-blind studies to evaluate the safety and efficacy of ceftaroline versus vancomycin plus aztreonam in complicated skin and skinstructure infection. Clin Infect Dis. 2010;51(6):641-50.

65. Moran GJ, Fang E, Corey GR, Das AF, De Anda C, Prokocimer P. Tedizolid for 6 days versus linezolid for 10 days for acute bacterial skin and skin-structure infections (ESTABLISH-2): a randomised, double-blind, phase 3, non-inferiority trial. Lancet Infect Dis. 2014;14(8):696-705.

66. Corey GR, Kabler H, Mehra P, Gupta S, Overcash JS, Porwal A, et al. Single-dose oritavancin in the treatment of acute bacterial skin infections. N Engl J Med. 2014;370(23):2180-90.

67. Boucher HW, Wilcox M, Talbot GH, Puttagunta S, Das AF, Dunne MW. Once-weekly dalbavancin versus daily conventional therapy for skin infection. N Engl J Med. 2014;370(23):2169-79.

68. LeBlanc L, Pepin J, Toulouse K, Ouellette MF, Coulombe MA, Corriveau MP, et al. Fluoroquinolones and risk for methicillin-resistant Staphylococcus aureus, Canada. Emerg Infect Dis. 2006;12(9):1398-405.

69. Aldeyab MA, Harbarth S, Vernaz N, Kearney MP, Scott MG, Darwish Elhajji FW, et al. The impact of antibiotic use on the incidence and resistance pattern of extended-spectrum beta-lactamase-producing bacteria in primary and secondary healthcare settings. Br J Clin Pharmacol. 2012;74(1):171-9.

70. Paterson DL. "Collateral damage" from cephalosporin or quinolone antibiotic therapy. Clin Infect Dis. 2004;38(Suppl 4):S341-5.

71. Liu C, Bayer A, Cosgrove SE, Daum RS, Fridkin SK, Gorwitz RJ, et al. Clinical practice guidelines by the Infectious Diseases Society of America for the treatment of methicillin-resistant Staphylococcus aureus infections in adults and children: executive summary. Clin Infect Dis. 2011;52(3):285-92.

72. Gupta K, Hooton TM, Naber KG, Wullt B, Colgan R, Miller LG, et al. International clinical practice guidelines for the treatment of acute uncomplicated cystitis and pyelonephritis in women: a 2010 update by the Infectious Diseases Society of America and the European Society for Microbiology and Infectious Diseases. Clin Infect Dis. 2011;52(5):e103-20.

73. Centers for Disease Control and Prevention. Antibiotic-resistant Gonorrhea. December 6, 2017. https://www.cdc.gov/std/gonorrhea/arg/. Accessed 5 Feb 2018. 